\title{
A Importância da Ambientação Vintage para a Sustentabilidade
}

\author{
The importance of Vintage Ambiance for sustainability
}

ARAÚJO, Kátia Maria de Lima; M.a.; UNIFBV

katia.araujo@unifbv.edu.br

\section{Resumo}

Entre as atribuições do Designer de Interior está a busca por soluções estratégicas para a preservação do meio ambiente, como o incentivo ao reaproveitamento de materiais, especificando produtos que sobrevivam ao seu ciclo de vida. A Ambientação Vintage enquadra-se entre estes objetivos, uma vez que o prolongamento da vida útil do mobiliário, entre outras questões, reduz os resíduos provenientes da confecção de móveis novos, justificando a presente pesquisa. $O$ artigo tem por objetivo verificar até que ponto, na visão do universo pesquisado, esse tipo de design de interior é importante para a sustentabilidade. Com abordagem quantitativa-qualitativa, e caracterizada como estudos de casos múltiplos, seus resultados apontam para o entendimento de que os respondentes não são leigos sobre o assunto, cabendo às instituições e profissionais da área propagarem essa possibilidade de ambientação, que se apresenta como uma das formas de colaborar com o desenvolvimento sustentável.

Palavras Chave: ambientação; vintage; design de interior e sustentabilidade.

\begin{abstract}
Among the tasks of the Interior Designer's quest for strategic solutions for the preservation of the environment, such as encouraging the reuse of materials, specifying products that survive to your lifecycle. The Vintage Ambiance fits between these goals, since the extension of the useful life of furniture, among other things, reduces the wastes from production of new furniture, justifying this research. The article aims to verify the extent to which, in the view of the universe researched, this kind of interior design is important for sustainability. The result of quantitative and qualitative research, characterized as multiple case studies, points to the understanding that the respondents are not laymen on the subject, and the institutions and professionals in the field spreading this possibility of ambiance, that presents itself as one of the ways to contribute to sustainable development.
\end{abstract}

Keywords: ambiance; vintage; interior design and sustainability. 


\section{Introdução}

Conseguir manter-se inserido na sociedade contemporânea, sem causar prejuízo ao meio em que vivemos, é um desafio diário aos cidadãos, uma vez que toda ação gera consequências que podem ser positivas ou negativas ao meio ambiente. No Brasil, assim como em diversos países do mundo, várias organizações ${ }^{1}$ estão engajadas em promover a conscientização da sociedade, visando a preservação do meio ambiente e a consequente necessidade de atitudes sustentáveis.

Inserida em um contexto bastante amplo, a sustentabilidade é estruturada em três pilares: ambiental, social e econômico, ou seja, no ambientalmente correto, no socialmente justo e no economicamente viável. Na prática, o economicamente viável, estaria relacionado às atividades humanas que objetivam suprir as necessidades do ser humano sem agredir o meio ambiente (MMA, 2014a).

Neste interim, a ambientação vintage, por aumentar a vida útil de um produto, vem colaborar com a sustentabilidade, pois o descarte de um móvel em um local inadequado transforma-se em entulho, visto que os materiais que o compõem podem não ser biodegradáveis. Além de valorizar nosso passado, o não descarte de um móvel antigo também colabora para a redução de insumos, redução da utilização de fontes naturais e redução de custos operacionais, necessários para a confecção de móveis novos, reduzindo também os resíduos provenientes dessa confecção (BRASIL, 2005; PELTIER E SAPORTA, 2009; MMA, 2014b)

Baseado em dados qualitativos e quantitativos, mas também em revisão bibliográfica estruturada no contexto da preservação do meio ambiente, este artigo tem por objetivo verificar até que ponto, na visão do universo pesquisado composto por professores, alunos e egressos de uma IES particular, a ambientação vintage é importante para a sustentabilidade. É uma abordagem desafiadora, na medida em que vai de encontro a padrões de consumo e à atividade do designer de interior, cujas atribuições relacionam-se aos processos de criação e inovação.

Justifica-se, porém, devido ao fato de que o designer, como profissional responsável, também precisa encontrar soluções estratégicas para a preservação do eco sistema e do crescimento socioambiental.

\section{Vintage ou Retrô?}

Ambientar é criar cenários. A partir da disposição de móveis e objetos, em harmonia com cores, texturas e iluminação, cria-se o cenário de jantar, o cenário de dormir, o cenário de trabalhar, o cenário de recrear. O móvel, parte integrante desse cenário, cumpre a função de ser útil, sendo também adorno, e em composição com seu entorno, representa os valores, as crenças e demais particularidades inerentes à identidade de quem o possui. Não que o móvel e seu entorno tenham significados por eles mesmos, mas sim, na projeção que as pessoas imprimem à composição. (NORMAN, 2005; MALTA, 2011; CIANCIARDINI, 2016).

Possuir objetos e mobiliário, organizá-los em forma de cenário faz parte de uma cultura de ambientação que se desenvolveu ao longo dos séculos. Sumariamente, pontuando a decoração de ambientes em sua trajetória histórica, vemos sua transição de símbolo de poder e riqueza entre as civilizações antigas, passando por vários períodos históricos, quando apenas os mais abastados

\footnotetext{
${ }^{1}$ Ministério do Meio Ambiente - MMA; Instituto Brasileiro de Sustentabilidade - INBS; Fundação Israel Pinheiro - FIP; Comissão da Carta da Terra, elaborada pela Organização das Nações Unidas - ONU; entre outras.
} 
possuíam condições de ter ambientes decorados, percorrendo um longo caminho até meados do século XIX, quando a decoração de interiores deixou de ser privilégio de alguns e alcançou pessoas de classes sociais mais simples (OATES, 1991; MALTA, 2011).

Nesse ínterim, entre os vários períodos históricos, a classificação da ambientação, por estilos, reflete ora a intenção de novo, ora a intenção de nostalgia. Encontramos o novo no Renascimento do século XV, por exemplo, quando, com a expansão da atividade mercantil, os novos ricos patrocinaram artistas como Michelangelo, Leonardo da Vinci, Rafael, que fizeram renascer das cinzas uma nova maneira de fazer arte; ou no Rococó do século XVIII, cuja intensão era diminuir os excessos do barroco; o Art Nouveau, que pretendia se desapegar a todas as amarras que o prendessem ao passado; ou ainda, em um período mais próximo ao nosso, a Bauhaus, escola, mas também estilo, que mesmo inspirada nos movimentos anteriores De Stijl e Arts and Crafts, além de resolver problemas de estilismo para a indústria, pretendia substituir os ambientes escuros pela nova forma de morar (OATES, 1991; BÜRDEK, 2006; CORBUSIER, 2014).

Entremeando o novo, vez por outra, vemos uma necessidade de retorno ao passado. $A$ nostalgia presente no período Eclético em meados do século XVIII, procurava trazer de volta os períodos anteriores, cujas denominações adquiriram o "neo" precedendo seus nomes, surgindo dessa forma, o neo-barroco, neo-gótico, neo-renascimento, que apesar de significar "novo", reproduzia os estilos passados. Ou o Arts \& Crafts, movimento contra a má qualidade dos produtos ecléticos, cujo precursor William Morris, defendia o retorno às tradições artesanais da Idade Média (OATES, 1991).

Por nostalgia, não entendemos como sendo uma necessidade do velho ou do retrógrado, mas como uma recuperação ou valorização do passado, um sentimento agradável que nasce da interação entre homem e objeto, motivada pela história que lhes são inerentes. Os aspectos sentimentais, inclusive, gerados através da utilização de produtos antigos, têm sido estudados pela teoria do Design Emocional que investiga o prazer e as emoções em adquirir produtos, sentimentos estes, que vão além da satisfação ou insatisfação, como o de nostalgia, por exemplo (JORDAN, 1998; NORMAN, 2005; BEBIANO, 2006). Retrô.

Atualmente, temos duas novas denominações para o retorno à nostalgia: o Vintage e o

Em uma ambientação retrô, são utilizados móveis e objetos confeccionados na atualidade, porém, com design de estilos passados, ou seja, são réplicas ou releituras. Nos exemplos da figura 1 , todos os produtos são inspirados em modelos do século XX, mais precisamente, nos anos 60 , como a televisão LG, com pés palito e formato em tubo, porém com o sistema de controle remoto;

Figura 1: Exemplos de produtos retrô.
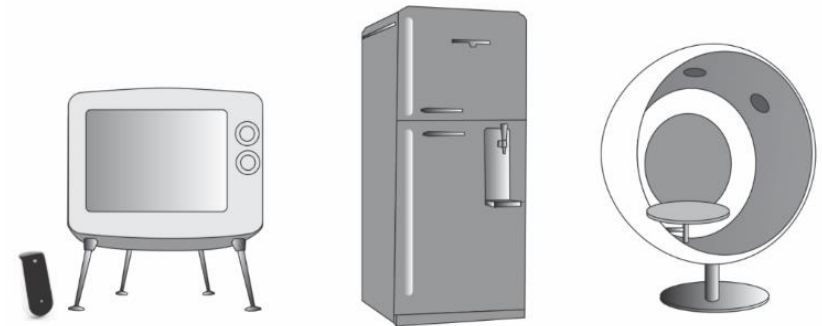

Fonte: própria. 
a geladeira Brastemp frost free, com controle eletrônico externo; a cadeira Sonic Chair do Designer Holger Fritzlar, criada em 2007, remete à Delta Ball Chair do Designer Eero Aarnio, mas, com sistema de som e entrada para iPad ou computador portátil.

Já em uma ambientação vintage são utilizados móveis e objetos antigos, organizados, ou não, em um contexto contemporâneo. Quer sejam adquiridos em leilões, por herança, ou em brechós, para ser considerada vintage, as peças devem ter sido confeccionadas nos séculos anteriores ao atual, originais, e que, por sua qualidade material, sobreviveram ao longo dos anos, estando aptas para continuarem a ser úteis (MONCADA E ALVIM, 2013 e 2017; CAMINHO DOS ANTIQUARIOS, 2018).

Utilizando símbolos de momentos históricos, a ambientação vintage cria cenários procurando valorizar a natureza sentimental do passado, remetendo a um período da nossa história, um lugar, recriado, não da mesma forma em que existiu nesse passado, mas a partir das aspirações e necessidades atuais.

Na figura 2, vemos pequenos exemplos desse tipo de ambientação, onde são usados móveis antigos organizados em um novo contexto, compondo o ambiente com peças contemporâneas. Nos dois ambientes, os móveis resistiram ao tempo e estão em condições de continuarem a ser usados.

Figura 2: Exemplos de ambientações vintage.
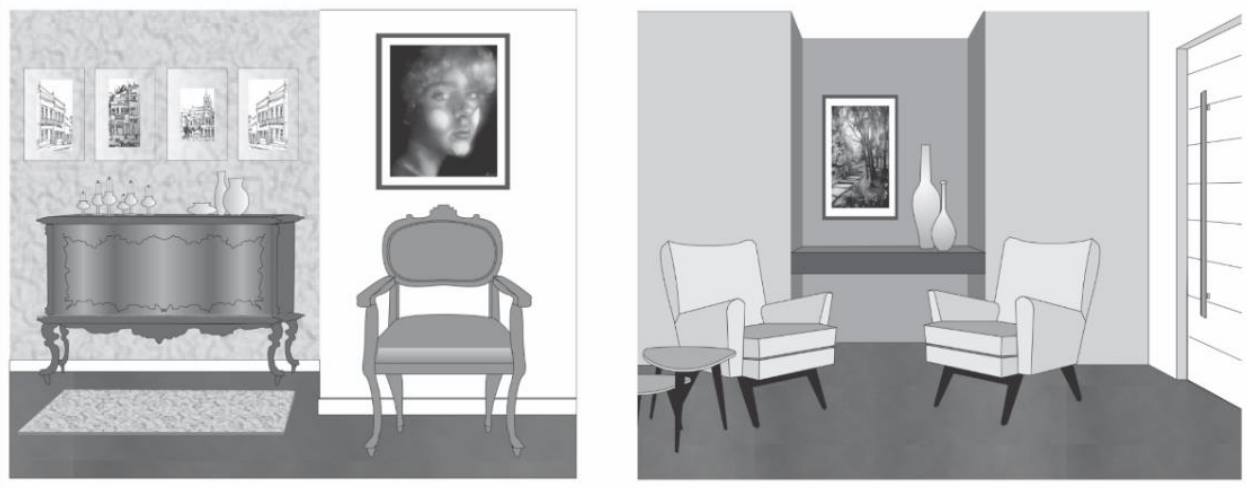

Fonte: própria.

O mobiliário e utensílios de uma ambientação vintage podem agradar a clientes de várias classes sociais, tanto aos que desembolsam valores altos por móveis adquiridos em antiquários e leilões, quanto, aos que customizam móveis avariados adquiridos em demolições ou em brechós.

Em antiquários as peças são avaliadas a partir de critérios que vão além de um olhar curioso, como a qualidade do material, o estado de conservação e a procedência. A raridade do objeto é um outro critério que faz com que peças pequenas consigam, muitas vezes, atingir valores maiores do que peças grandes; o estilo também é um fator relevante e está atrelado ao período em que foi confeccionado, como o período Barroco, Art Nouveau, Art Decó, etc., cujas características devem estar de acordo com as técnicas e limitações da época; o tempo também é levado em consideração ${ }^{2}$,

\footnotetext{
2 Nos Estados Unidos só é considerada uma antiguidade peças com mais de 100 anos. No Brasil são encontradas peças da década de 50, enquanto na Europa é possível encontrar peças com mais de 400 anos (CAMINHO DOS ANTIQUARIOS, 2018).
} 
que por sua vez remete a qualidade do material, valoroso também por sua resistência (MONCADA E ALVIM, 2013 e 2017; CAMINHO DOS ANTIQUARIOS, 2018).

Todos esses critérios encarecem o mobiliário antigo, porém, vem surgindo outra maneira de projetarmos a ambientação vintage, de forma a torna-la acessível a uma maior quantidade de pessoas: a customização e restauração de mobiliário antigo adquiridos em demolições ou em brechós.

A customização proporciona uma possibilidade de intervenção para o designer de interior rejuvenescendo, agregando valor, readaptando ao uso diário uma peça que estaria condenada ao descarte. Resgata valores históricos, mas também econômicos, pois um móvel customizado custa, em média, 30\% do valor de um móvel novo (SEBRAE, 2018).

Na figura 3, vemos essa variante da ambientação vintage. Neste caso, como o móvel está com o revestimento muito avariado, necessitando de reparos, está sendo proposto uma intervenção, que poderá ser feita com pintura, adesivação, revestimento com folheado, etc.

Figura 3: Móvel antigo e 04 propostas para novo revestimento.
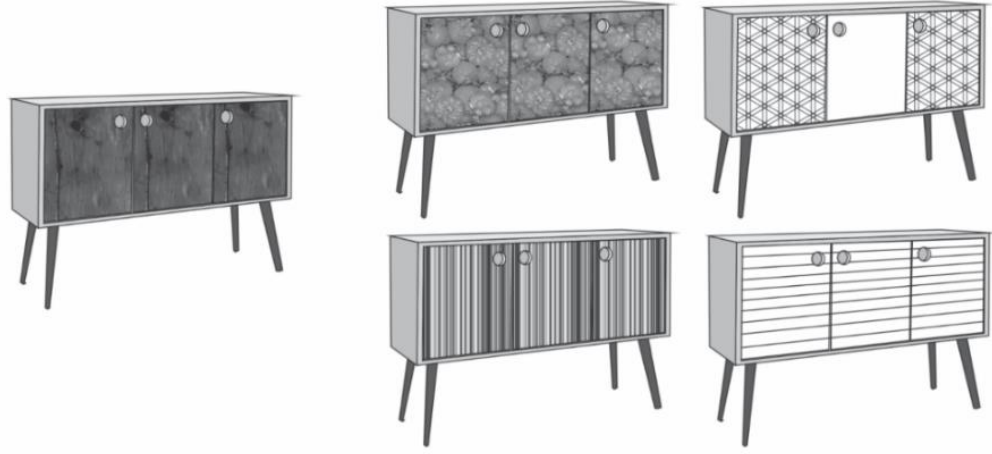

Fonte: própria.

Sob o ponto de vista das emoções, tanto o retrô quanto o vintage promoveriam a interação entre os seres humanos, em maior ou menor grau, pois sua utilização estaria atrelada a valorização dos aspectos socioculturais, mas também ao apego ao simbolismo das características formais antigas.

No entanto, entre o retrô e o vintage, temos na ambientação vintage atributos ecologicamente mais sustentáveis, visto que a utilização ou reutilização de objetos e mobiliário antigos aumenta sua vida útil reduzindo os insumos, os custos operacionais, e os resíduos provenientes da confecção de móveis novos, aspectos que veremos a seguir.

\section{0 descarte e a formação de resíduos}

Uma das funções do designer de interior é criar ambientações tomando por base o eco design. Este objetiva o planejamento de espaços e produtos estudando o ciclo de vida dos mesmos, procurando reduzir o uso de recursos não renováveis, e com isso minimizar o impacto ambiental. Preocupa-se também com a escolha da matéria-prima e materiais utilizados em sua confecção, prevendo desde o projeto, o processo de fabricação, sua produção, transporte, seu uso, e finalmente, seu descarte, responsável pela formação de entulhos. 
O princípio dos Três Erres (3R's) - reduzir, reutilizar e reciclar, surge como incentivo à prevenção e não-geração de resíduos, como: a redução do consumismo; a aquisição de produtos mais duráveis; o aumento da vida útil do produto; e a criação de artefatos a partir de materiais que já foram usados. (BRASIL, 2005; PELTIER E SAPORTA, 2009; INBS, 2016).

Reciclar é sustentável, mas nem tudo pode ser reciclado. No processo construtivo de móveis, suas indústrias deparam-se com o acúmulo de sobras de materiais, que por sua vez, trazem consequências negativas, como o desperdício de matérias-primas, os custos provenientes da coleta e tratamento do lixo; dificuldade para encontrar áreas disponíveis para sua disposição final; e, quando depositado em locais inadequados contaminam a área em que está alocado.

A quantidade de materiais existentes no mercado, voltados para ambientação, é bastante diversificada. De forma resumida, veremos a seguir, os resíduos gerados na confeç̧ão de móveis e objetos em madeira, vidro e metal $^{3}$, como podem ser reaproveitados e o que não pode ser reciclado:

\subsection{Madeira}

Quando se fala na utilização da madeira, geralmente, se associa a sua utilização a um ato ilegal. A depredação histórica das árvores remete desde o século XVI, quando, em nosso país, o Paubrasil foi extremamente explorado pelos europeus, sendo que, sua extração ilegal, assim como, a de várias outras espécies, ainda continua sendo assunto relevante e constante preocupação dos órgãos responsáveis (SOUZA JR., 2007).

Entretanto, a utilização da madeira pode ser sustentável, e para discutir esse item, vamos nos ater à confecção de móveis em madeira maciça certificada e madeira transformada, como os compensados, MDF, etc., provenientes do bom manejo, de reflorestamento, e de demolição.

Os resíduos de madeira surgem desde seu processamento nas laminadoras, quando fabricam as peças, os painéis compensados e os reconstituídos. Nas indústrias de móveis, que podem ser de pequeno, médio e grande porte, além das sobras provenientes da madeira, são produzidos resíduos provenientes de outros materiais como plástico, ferro, vidro, tecido, espuma, etc., a depender do tipo de móvel, que pode ser feito sob medida ou em série (CASAGRANDE JR., 2004).

Em si tratando apenas da madeira, suas sobras são denominadas por cavacos, tocos, restos dos processos de serragem e peças com defeito, vendidos para empresas de painéis reconstituídos, olarias, padarias, granjas, etc., porém, seu destino final ou seu reaproveitamento vai depender da estrutura da serraria. Nas empresas de pequeno porte o controle do seu descarte é menor, sendo sua coleta e reaproveitamento menos eficiente. (Idem).

As sobras de madeira maciça não são tóxicas, porém as provenientes de madeira transformada, como os compensados, por possuírem resinas fenólicas, e os painéis de média densidade - MDF, por terem em sua composição o formaldeído, por exemplo, precisam de maior atenção em seu descarte.

\subsection{Vidro}

Em design de interior são utilizadas peças de vidro de vários tipos, formatos, e em composição com outros materiais. Possuindo várias aplicações, encontramos vidro em janelas,

\footnotetext{
${ }^{3}$ Foram analisados, de forma resumida, os três materiais mais encontrados em ambientação, atualmente.
} 
portas, divisórias, tampos de mesa, aparadores, espelhos, prateleiras, etc.

O vidro é composto basicamente por areia (72\%), barrilha (14\%), calcário (11\%) e alumina (2\%), à uma temperatura de 1500 $\mathrm{C}$, transforma-se em uma massa em estado plástico de altíssima viscosidade, enrijecendo-se à medida em que se resfria. É fabricado a partir de dois processos de fundição: o artesanal, feito por sopro, produzindo, geralmente, embalagens e objetos de arte; e o industrial, feito em tanques refratários, que produz chapas e folhas de vidro. (DIAS E CRUZ, 2009).

O vidro não é um produto biodegradável, mas pode ser $100 \%$ reciclável, dependendo dos materiais que foram adicionados na sua composição básica, como os vidros do tipo cristal que recebem estanho líquido; os espelhos que recebem jateamento de nitrato de prata ou nitrato de cobre; e os serigrafados, que recebem esmalte cerâmico; esses componentes podem ocasionar menos resistência, bolhas ou alteração aos novos produtos, inibindo sua reciclagem (LIMA, 2006).

No Brasil, o índice de reciclagem do vidro está em $47 \%$, oriundos da indústria de embalagens e $10 \%$ provenientes de bares, hotéis, residências, etc. Seu processo começa a partir da coleta seletiva e da entrega em Unidades de Recebimento de Pequenos Volumes - URPVs e Postos de Entrega Voluntária - PEVs, porém, alguns entraves dificultam o processo, como seu peso, que aumenta o custo do transporte, e o seu descarte em locais inadequados. (DIAS E CRUZ, 2009; PELTIER E SAPORTA, 2009).

\subsection{Metal}

Na decoração de ambientes encontramos o metal em diversos produtos. É um material maleável que permite várias intervenções, podendo ser cortado, perfurado, dobrado, forjado, trefilado, sinterizado e fundido, possibilitando sua aplicação em esquadrias, divisórias, corrimãos, móveis, cadeiras, objetos de arte, luminárias, etc. (LIMA, 2006).

Resumindo o processo de confecção do ferro, são extraídos da natureza os minérios hematita e magnetita. $E$ em um forno à $1500^{\circ} \mathrm{C}$, a esses minérios são adicionados o carvão coque (combustível) e o calcário (fundente), formando o ferro gusa, líquido flamejante, despejado em lingoteiras, e que quando resfriado, formarão os lingotes de ferro. (ASHBY E JOHNSON, 2011).

Desses lingotes são criados o ferro fundido, obtido através da mistura de outros metais carbono $(\mathrm{C})$, silício $(\mathrm{Si})$ e manganês $(\mathrm{Mn})$ para obtenção de diferentes ligas de ferro, com o intuito de melhorar suas propriedades, pois, em contato com o oxigênio, o ferro fundido desgasta-se, oxidando-se. Para protegê-lo da corrosão recomenda-se a aplicação de galvanização ou a aplicação de pintura eletrostática, por exemplo.

Dos lingotes de ferro, também obtemos o aço. A este, por sua vez, são adicionados cromo $(\mathrm{Cr})$, níquel ( $\mathrm{Ni}$ ) e molibdênio (Mo). Juntos protegem o metal contra o desgaste, quando em contato com o oxigênio, ou seja, dificilmente oxida, por esse motivo, ao contrário do ferro fundido, o inox não necessita de revestimentos posteriores. (ASHBY E JOHNSON, 2011).

Os metais não ferrosos também não oxidam, e cada um tem a sua forma de ser extraído da natureza e método próprio de ser confeccionado.

Em si tratando de sustentabilidade, o metal é um produto $100 \%$ reciclável, o que o torna um produto sustentável. Quando finda a sua vida útil, transforma-se em sucata, retornando a cadeia produtiva sem perder a qualidade. Na confecção dos produtos de metal, as empresas se preocupam em encontrar meios para que haja melhoria do aproveitamento do material, a partir da eficiência 
do corte, e na gestão de retalhos, que devem ser armazenados para posterior reaproveitamento, ou vendidos para os recicladores (PELTIER E SAPORTA, 2009; SANTOS ET.AL., 2015).

Com relação aos resíduos provenientes de materiais metálicos, os aços e os metais não ferrosos, por não oxidarem, teriam uma vida útil maior, justificando sua utilização em ambientações vintage.

A proposta desse tipo de ambientação, entretanto, é um desafio para o designer de interior. A dimensão social inserida em suas atribuições o convida a pensar e criar de forma ecológica: ao projetar ambientes, ao desenvolver produtos e ao executar serviços. No Brasil, o Ministério do Meio Ambiente - MMA (2014b), estabelece os seguintes princípios, relacionados aos objetivos do eco design:

Tabela 1: princípios, relacionados aos objetivos do eco design

1. Projetar escolhendo materiais menos poluentes, não tóxicos, de produção sustentável, recicláveis, visando o baixo impacto ambiental, na sua produção e quando em seu descarte.

2. Visar a minimização do consumo de energia nos processos de fabricação.

3. Criar produtos mais duráveis a fim de gerar menos lixo.

4. Adotar a modularidade, criando objetos com peças intercambiáveis, que possam ser trocadas em caso de defeito, evitando a troca de todo o produto, gerando menos lixo.

5. Incentivar a reutilização e o reaproveitamento, projetando ambientes e especificando produtos que sobrevivam ao seu ciclo de vida.

Fonte: adaptado de MMA (2014b)

Vê-se que a ambientação vintage enquadra-se no terceiro e quinto princípios. Sua utilização, porém, esbarra em vários entraves: no cliente, que dá o aval para a confecção do projeto de ambientação; nas tendências de mercado, que elegem o estilo da moda; e, de uma maneira geral, na falta de atitude dos que conhecem a teoria da sustentabilidade, mas não a colocam em prática.

As campanhas de conscientização, entretanto, difundidas por várias organizações ${ }^{4}$, têm obtido alguns resultados, como mostram os dados da pesquisa apresentados a seguir.

\section{Metodologia}

A presente pesquisa possui caráter empírico, posto que se apoiou nas experiências dos entrevistados e na observação dos fatos, porém, foi feita uma revisão na literatura, a fim de encontrar respaldo teórico para os constructos ambientação vintage, design de interior e sustentabilidade.

O lócus da pesquisa foi uma IES particular situada na Região Metropolitana de Recife - PE, e os sujeitos compostos por professores, alunos e egressos da mesma, num total de 54 respondentes. Os dados foram coletados por meio de questionário auto administrado surveymonkey intitulado "Sustentabilidade em Design de Interior", com questões abertas e fechadas, o que caracterizou uma abordagem do tipo multimétodos ${ }^{5}$.

A pesquisa foi feita em dois momentos: no primeiro, o questionário foi enviado para os e-

\footnotetext{
${ }^{4}$ Comissão da Carta da Terra, elaborada pela Organização das Nações Unidas - ONU, Ministério do Meio Ambiente MMA; Instituto Brasileiro de Sustentabilidade - INBS; Fundação Israel Pinheiro - FIP; entre outros.

${ }^{5}$ Análise de dados de forma qualitativa e quantitativa.
} 
mails de alunos e egressos do curso de design da instituição pesquisada; em um segundo momento o mesmo questionário foi enviado para os e-mails de professores dos cursos de engenharia, administração, nutrição, direito, arquitetura e design, da mesma IES, caracterizando-se como estudos de casos múltiplos (MAZZOTTI, 2006).

Analisando as 54 respostas verificou-se a opinião destes, a respeito de sua responsabilidade e de suas atitudes frente as questões em pauta.

$\mathrm{Na}$ abordagem quantitativa, as questões fechadas foram formatadas pelo próprio questionário auto administrado surveymonkey, mas analisadas pela pesquisadora. Foi utilizada a escala Likert de três e de quatro pontos, gerando informações que auxiliaram a compreensão de vários quesitos achados na abordagem qualitativa.

$\mathrm{Na}$ abordagem qualitativa, as respostas abertas do questionário foram contabilizadas por frequência e tratadas através da análise de conteúdo, identificando as unidades de significação correspondentes ao conteúdo analisado (BARDIN, 2011). Foi utilizado o tema para classificá-las, agrupá-las e analisá-las pela frequência em que surgiram, gerando dois grupos de categorias: um relacionado à sustentabilidade e outro à ambientação vintage.

\section{Resultados da pesquisa}

O perfil dos respondentes, exposto na tabela a seguir, pode ser resumido da seguinte forma: público adulto, em sua maioria do sexo feminino, a maioria de nível superior.

Tabela 2: Caracterização dos 54 respondentes.

\begin{tabular}{llcc}
\hline CARACTERIZAÇÃO DOS RESPONDENTES & $f$ & $f R(\%)$ \\
\hline \multirow{4}{*}{ Gênero } & Feminino & 38 & 70,37 \\
\cline { 2 - 4 } & Masculino & 15 & 27,78 \\
\cline { 2 - 4 } & Outros & 1 & 1,85 \\
\hline \multirow{3}{*}{ Faixa etária } & Entre 18 e 25 anos & 13 & 24,08 \\
\cline { 2 - 4 } & Entre 26 e 35 anos & 19 & 35,19 \\
\cline { 2 - 4 } & Entre 36 e 45 anos & 5 & 9,25 \\
\cline { 2 - 4 } & Mais de 50 anos & 25 & 31,48 \\
\hline \multirow{3}{*}{ Escolaridade } & Segundo grau completo & 8 & 14,29 \\
\cline { 2 - 4 } & Terceiro grau completo & 21 & 38,89 \\
\cline { 2 - 4 } & Pós-graduados & & \\
\hline
\end{tabular}

Fonte: Elaboração própria, com base nos dados da pesquisa.

Quase todos os entrevistados responderam ter conhecimento das expressões referentes à conceitos e atitudes ecologicamente corretas, como nos mostra o gráfico a seguir:

Gráfico 1: Expressões referentes à conceitos e atitudes ecologicamente corretas.



Fonte: Elaboração própria, com base nos dados da pesquisa. 
A expressão menos conhecida foi eco design, $48,39 \%$. As demais variaram entre $91,43 \% \mathrm{e}$ $100 \%$ de conhecimento.

Esse fator também foi registrado nas respostas às duas questões abertas: "O que você entende por sustentabilidade?" e "Você já ouviu falar em ambientação Vintage? Você usaria em sua residência?", que foram analisadas e contabilizadas por frequência. O índice de surgimento das palavras, sua ordenação e o vocabulário dos respondentes foram indicadores da probabilidade de conhecimento sobre o assunto em pauta.

Os dois grupos de categorias, um relacionado à sustentabilidade e outro à ambientação vintage, são os seguintes:

\subsection{Categorias relacionadas à sustentabilidade}

As unidades de significação encontradas nas respostas à primeira pergunta, "O que você entende por sustentabilidade?", apontaram para um público que tem conhecimento sobre várias questões relacionadas à sustentabilidade.

Das unidades de significação emergiram 05 categorias pertinentes à relação entre sustentabilidade e o respeito ao meio ambiente, a agressão à natureza face ao descompromisso e falta de atitudes ecologicamente corretas, à necessidade de consumo sustentável, visando nossa sobrevivência e das gerações futuras, como mostra a tabela 3:

Tabela 3: Categorias para a resposta à "O que você entende por sustentabilidade?".

\begin{tabular}{|c|c|c|c|c|}
\hline CATEGORIAS I & $\begin{array}{l}\text { UNIDADES DE } \\
\text { SIGNIFICAÇÃO }\end{array}$ & $f$ & $f R(\%)$ & Total \\
\hline \multirow{4}{*}{ Respeito ao meio ambiente } & Meio ambiente & 18 & 18,58 & \multirow{4}{*}{39} \\
\hline & Recursos naturais & 10 & 10,34 & \\
\hline & Materiais da natureza & 6 & 6,18 & \\
\hline & Natureza & 5 & 5,15 & \\
\hline \multirow{5}{*}{ Agressão ao meio ambiente } & Impacto negativo & 11 & 11,34 & \multirow{5}{*}{26} \\
\hline & Agredir/agressão & 4 & 4,12 & \\
\hline & Prejudicar/prejuízo & 5 & 5,15 & \\
\hline & Comprometer & 3 & 3,09 & \\
\hline & Causar danos & 3 & 3,09 & \\
\hline \multirow{4}{*}{ Consumo sustentável } & Consumo/consumir & 8 & 8,24 & \multirow{4}{*}{20} \\
\hline & Produção/produzir & 7 & 7,21 & \\
\hline & $\begin{array}{l}\text { Utilização de materiais da } \\
\text { natureza }\end{array}$ & 3 & 3,09 & \\
\hline & $\begin{array}{l}\text { Extração de materiais da } \\
\text { natureza }\end{array}$ & 2 & 2,06 & \\
\hline \multirow{2}{*}{ Sobrevivência no futuro } & Gerações futuras & 6 & 6,18 & \multirow{2}{*}{10} \\
\hline & Futuro & 4 & 4,12 & \\
\hline Não sabe o que significa & & 2 & 2,06 & 2 \\
\hline \multicolumn{2}{|c|}{ TOTAL (de unidades de significação, e não de respondentes) } & 97 & $100 \%$ & 97 \\
\hline
\end{tabular}

Fonte: Elaboração própria, com base nos dados da pesquisa.

Para ilustrá-la, seguem alguns depoimentos dos respondentes:

"Sustentabilidade é cuidar do nosso planeta, realizando ações e atitudes que possam torna- 
lo melhor, também pode ser definida como uma capacidade de o ser humano interagir com o mundo, preservando o meio ambiente cada vez mais" (R07).

Utilizar os materiais (principalmente os não renováveis) de um modo consciente para garantirmos que os mesmos ainda existam nas gerações futuras (R.29)

Todo universo criado a partir de técnicas pouco invasivas ao meio ambiente, que prejudiquem o mínimo seja por novos projetos ou reaproveitamento (R.36).

O resultado aponta para o efeito das campanhas de conscientização da população, sobre atitudes sustentáveis, promovidas pelas organizações e instituições nacionais e internacionais; e também, por ser um público letrado, a maioria proveniente de cursos superiores, possivelmente, tratam ou já trataram sobre esse assunto em sala de aula.

\subsection{Categorias relacionadas à ambientação vintage}

As unidades de significação encontradas nas respostas à segunda pergunta "Você já ouviu falar em ambientação Vintage? Você usaria em sua residência?", indicam que a maioria dos respondentes se mostra favorável a esse estilo de ambientação, e que não é leiga sobre o assunto. Delas emergiram 04 categorias pertinentes à relação usuário e produto, como mostra a tabela 4:

Tabela 4: Categorias para a resposta à "Você já ouviu falar em ambientação Vintage? Você usaria em sua residência?".

\begin{tabular}{lcc}
\hline \multicolumn{1}{c}{ CATEGORIAS II } & $\boldsymbol{f}$ & $\boldsymbol{f R}(\%)$ \\
\hline Conhecia e usaria, pois, se identifica com o estilo & 41 & 75,93 \\
\hline Não conhecia e não usaria, pois, não se identificou com o estilo & 8 & 14,81 \\
\hline Conhecia, mas não usaria, pois, não se identifica com o estilo & 3 & 5,56 \\
\hline Não conhecia, mas usaria, pois, se identificou com o estilo & 2 & 3,70 \\
\hline TOTAL (de respondentes) & 54 & $100 \%$ \\
\hline
\end{tabular}

Fonte: Elaboração própria, com base nos dados da pesquisa.

Entre os depoimentos destacam-se:

"Sim, utilizaria com certeza, faz meu estilo" (R.09).

“Conheço. Não, por não ser o estilo que mais gosto" (R.10).

"Já ouvi falar e usaria se tivesse a ajuda de um designer de interiores para escolher as peças mais adequadas ao ambiente" (R.22).

“Nunca ouvi falar. Estou sempre aprendendo. Usaria sim. Com certeza". (R.44).

"Sim, um estilo de ambientação que está em alta nos últimos anos. Não, por questões da falta de identificação com o estilo (R. 47)

"Já, usaria com toda certeza. São ótimas peças que ressaltam uma exclusividade e charme. (R. 50)

Percebe-se que a maioria dos respondentes, $75 \%$, já conhecia a ambientação vintage e se identifica com ela; $14,81 \%$ não se identificou após a pesquisa; $5,56 \%$ não se identifica com o estilo; e 3,70\% se identificou com o estilo após a pesquisa. Entre as unidades de significação que geraram as categorias acima apareceram: estilo, identificação, charme, elegância, exclusividade e adequação, concordando com a teoria do Design Emocional que fala sobre a empatia na interação entre homem e objeto, investigando o prazer em adquirir produtos, e que vai além da satisfação ou 
insatisfação.

Os respondentes, porém, associaram a ambientação vintage apenas a um estilo. Não citaram sua qualidade de sustentável, nem vislumbraram a possibilidade de, em se aproveitando um móvel antigo e aumentando sua vida útil, estariam colaborando para a redução de resíduos. Também não associaram esta ambientação a questão do consumo sustentável.

Entretanto, diferente da questão fechada, "O que você acha do reaproveitamento de móveis para auxiliar na sustentabilidade? ", na escala de 1 à 4 , sendo 1 para nada importante e 4 para importantíssimo, $72 \%$ dos respondentes acham importantíssimo o reaproveitamento de móveis, ou seja, aumentar a vida útil do produto, $24 \%$ acham importante, e apenas $4 \%$ acham pouco importante, sendo zero para nada importante, o que denota falta de conhecimento do que realmente é ambientação vintage.

Também foi perguntado entre as questões fechadas, sobre duas outras atitudes ecologicamente corretas: "Quando você compra tinta para pintar sua casa, você verifica o índice de emissão de toxidade (COVs)?"; e "Quando você compra um móvel ou peça de madeira maciça, você verifica se é de madeira certificada?".

Sobre o índice de toxidade (COVs), na escala de 1 à 3, sendo 1 para nunca, 2 para às vezes e 3 para sempre, mais da metade dos respondentes, $56 \%$, nunca o verifica na hora da compra, 32\% verifica às vezes e apenas $12 \%$ verifica sempre.

Sobre a verificação da certificação de produtos feitos em madeira maciça, na escala de 1 à $3,42 \%$ nunca verifica, $28 \%$ às vezes e $30 \%$, sempre verifica o certificado.

O resultado aponta, mais uma vez, para a questão das campanhas de conscientização da população sobre atitudes sustentáveis. Diferentemente do índice de toxidade (COVs), que pouco é abordado pela mídia, e pela questão de o desmatamento estar a mais tempo e constantemente sendo discutido, talvez a população consiga absorver e incorporar melhor essa necessidade, passando a adotá-la.

\section{Conclusão}

Possuir objetos e mobiliário, organizá-los em forma de cenário faz parte de uma cultura de ambientação que se desenvolveu ao longo dos séculos. O móvel, parte integrante desse cenário, representa os valores, a posição social, as crenças e demais particularidades intrínsecas à identidade de seu usuário.

Os objetos também evocam memória. Sobre esse aspecto, vimos que o valor simbólico do mobiliário antigo e a sua qualidade material, são critérios da ambientação vintage que os utiliza em um contexto contemporâneo.

Vimos que essa ambientação se enquadra entre os objetivos do eco design, uma vez que o prolongamento da vida útil do mobiliário pode reduzir os resíduos provenientes da confecção de móveis novos. Também pode agradar a clientes de várias classes sociais, tanto aos que desembolsam valores altos adquirindo antiguidades em leilões, quanto aos que customizam móveis antigos avariados encontrados em demolições ou em brechós, investindo menos da metade do valor de um móvel novo, readaptando ao uso diário uma peça que estaria condenada ao descarte.

Analisando os dados qualitativos da pesquisa, mesmo que o público pesquisado não tenha citado a qualidade de sustentável ao vintage, identificando-o como sendo, apenas, um estilo 
esteticamente agradável, os dados quantitativos mostraram outra possibilidade, na medida que a maioria dos respondentes acha importantíssimo o reaproveitamento de móveis para aumentar a vida útil do produto.

A questão da sustentabilidade exige da sociedade, como um todo, mudanças de atitude e de comportamento. As campanhas de conscientização que visam atitudes ecologicamente corretas, têm conseguido atingir seu objetivo no que tange ao entendimento de seu conceito, porém, não tem conseguido fazer a população agir de forma efetiva. Sabe-se muito, age-se pouco.

Esta pesquisa não se propõe a ser conclusiva, inclusive, sugere-se que novas pesquisas, com grupos diferentes, sejam feitas. Esta teve como objetivo fazer uma associação entre as atividades do designer de interior e a sua contribuição para a sustentabilidade, verificando a importância da ambientação vintage para as questões ecológicas, chegando à conclusão que, de forma despretensiosa, a mesma pode colaborar para o desenvolvimento sustentável.

\section{Referências}

ASHBY, Michael; JOHNSON, Kara. Materiais e design: arte e ciência da seleção de materiais no design de produto. 2. ed. Rio de Janeiro: Elsevier, 2011.

BARDIN, L. Análise de Conteúdo. São Paulo: Edições 70, 2011.

BEBIANO, R. Nostalgia e imaginação: dois factores dinâmicos num mundo global. ENCONTRO DE FILOSOFIA, A FILOSOFIA NA ERA DA GLOBALIZAÇÃO, 20., 2006, Coimbra. Anais... Coimbra: Reitoria da Universidade de Coimbra, 2006.

BRASIL. Consumo sustentável: Manual de educação. Brasília: Consumers International/ MMA/ MEC/IDEC, 2005. 160 p.

BÜRDEK, B. E. Design - história, teoria e prática do design de produtos. São Paulo: Blucher, 2006.

CAMINHO DOS ANTIQUARIOS. Dicas de Antiguidades. Porto Alegre, 2018. (http://caminhodosantiquarios.blogspot.com.br/p/dicas-de-antiguidades.html).

CASAGRANDE JR., E. F., et al. Indústria moveleira e resíduos sólidos: considerações para o equilíbrio ambiental. Revista Educação \& Tecnologia, v.8. Curitiba: CEFETPR, 2004. p. 209 - 228.

CIANCIARDINI, G. Psicologia para decoração. Revista Mente e Cérebro, n.204, jan. 2010. (http://www2.uol.com.br/vivermente/reportagens/psicologia_para_decoracao.html).

CORBUSIER, L. Por uma arquitetura. 7. ed. São Paulo: Perspectiva, 2014.

DIAS, G. G., CRUZ, T. M. de S. Plano de gerenciamento integrado de resíduos vítreos - PGIRV. Belo Horizonte: FEAM/FIP, 2009.

INBS. Instituto Brasileiro de Sustentabilidade. A Carta da Terra. São Paulo, 2013. (http://www.inbs.com.br/a-carta-da-terra).

JORDAN, Patrick W. Human factors for pleasure in product use. Applied Ergonomics. Vol. 29, No. 1, pg. 25-33, 1998.

LIMA, M. A. M. Introdução aos materiais e processos para designers. Rio de Janeiro: Moderna, 2006. 
MALTA, M. O olhar decorativo: ambientes domésticos em fins do século XIX no Rio de Janeiro. Rio de Janeiro: Mauad X FAPERJ, 2011.

MAZZOTTI, A. J. Usos e abusos dos estudos de caso. Cadernos de Pesquisa, v. 36, n. 129, p. 637-651, set./dez. 2006.

MMA - Ministério do Meio Ambiente. Produção e consumo sustentáveis. Brasília, 2014a. (http://www.mma.gov.br/responsabilidade-socioambiental/producao-e-consumo-sustentavel). ecodesign).

Ecodesign. Brasília, 2014b. (http://www.mma.gov.br/component/k2/item/7654MONCADA, M.; ALVIM, P. Antiguidades e Obras de Arte. Lisboa: SCRIBE, 2013.

. Antiguidades e Obras de Arte. Lisboa: SCRIBE, 2017.

NORMAN, Donald A. Emotional Design: Why We Love (or Hate) Everyday Things. New York: Basic Books, 2005.

OATES, P. B. História do mobiliário ocidental. Lisboa: Presença, 1991.

PELTIER, F., SAPORTA, H. Design sustentável: caminhos virtuosos. São Paulo: SENAC, 2009.

PRESTES, A. P., et.al. A Influência da Nostalgia no Consumo Simbólico e Material de Bens. CONGRESSO INTERNACIONAL EM COMUNICAÇÃO E CONSUMO, 3., 2013, São Paulo. Anais... São Paulo: COMUNICON, 2013.

ROHENKOHL. R. A. S. Design retrô: um desafio da contemporaneidade em reconhecimento ao passado. Unoesc \& Ciência - ACSA, Joaçaba, v. 2, n. 2, 2011. p. 147-153.

SANTOS, L. A. dos, et. al. (Re) aproveitamento de sucata no ramo metal-mecânico frente à sustentabilidade ambiental. Revista Eletrônica em Gestão, Educação e Tecnologia Ambiental Santa Maria, v. 19, n. 2, mai-ago., 2015. p. 830-847.

SEBRAE. Restauração de móveis. Portal SEBRAE, 2018. (http://www.sebrae.com.br/sites/PortalSebrae/ideias/como-montar-um-servico-de-restauracaode-moveis,fd587a51b9105410VgnVCM1000003b74010aRCRD).

SOUZA JUNIOR, J. R. de. Sistema nacional de proteção ambiental: polícia administrativa ambiental. Belo Horizonte: Del Rey, 2007.

YAMANARI, T. T. O "Vintage" e o "Retrô" como estratégias visuais. In: ENCONTRO INTERNACIONAL DE ESTUDOS DA IMAGEM, 1., 2013, Londrina. Anais... Londrina: ENEIMAGEM, 2013. 